\title{
Geoengineering Tensions
}

\author{
Adrian Currie
}

\section{Penultimate Version, forthcoming in Futures}

\section{Acknowledgements}

This paper has benefited greatly from discussions and feedback with Holly Lawford-Smith, Seán Ó hÉigeartaigh, Heather Douglas, Hugh Hunt, Andy Parker, Catherine Rhodes, Joshua Wells and three anonymous reviewers. This publication was made possible through the support of a grant from Templeton World Charity Foundation. The opinions expressed in this publication are those of the author(s) and do not necessarily reflect the views of Templeton World Charity Foundation.

\section{Abstract}

There has been much discussion of the moral, legal and prudential implications of geoengineering, and of governance structures for both the research and deployment of such technologies. However, insufficient attention has been paid to how such measures might affect geoengineering in terms of the incentive structures which underwrite scientific progress. There is a tension between the features that make science productive, and the need to govern geoengineering research, which has thus far gone underappreciated. I emphasize how geoengineering research requires governance which reaches beyond science's traditional boundaries, and moreover requires knowledge which itself reaches beyond what we traditionally expect scientists to know about. How we govern emerging technologies should be sensitive to the incentive structures which drive science.

\section{Introduction: Two Balloons}

The trajectory of technological development is not foreordained, and is sometimes shaped by particular - contingent-events (see various papers in Soler, Trizio \& Pickering 2015). Such events can motivate flurries of research, but can also constrain, block and warp investigation. I'm going to consider how a particular event, the SPICE (Stratospheric Particle Injection for Climate Engineering) group's decision to cancel a balloon launch, potentially affected the development of geoengineering. In reflecting on the case, I'll bring out two tensions that a successful science of geoengineering must navigate. The first tension is much discussed: between the moral and prudential arguments in favour of developing or researching such technology, and the worry that there might be problematic consequences for mere research (let alone deployment). Second, there is a tension between the kinds of factors which make science productive, and factors pertaining to the governance of geoengineering research. Specifically, geoengineering research involves speculative examination of the possibility of large-scale interventions, research which to some extent depends upon field experiments. Given the extent of public worry about such research, geoengineering looks like a 'bad bet' for scientists and their funders. I'm going to argue that these tensions should lead us to worry about both the kinds of strategies scientific communities have adopted to motivate responsible research for this potentially important technology, and about some proposed approaches to governance. My way in involves something of a conceit, and begins with a successful balloon launch.

Over 200 years ago, a balloon launch was instrumental in sparking both a craze for hot-air ballooning in Europe, and diverse scientific research; in 2012 a balloon was not launched, with consequences which are still playing out, but with the potential to stunt scientific research. 
On June $5^{\text {th }} 1783$, before an excited crowd gathered in a field in southern France, the Montgolfier brothers launched the late- $18^{\text {th }}$ Century's answer to Sputnik. A 30 foot-tall unmanned paper balloon drifted high into the clouds. This led to something of a mania for lighter-than-air craft. Although the brothers themselves had largely commercial motivations (the stunt was intended to advertise their paper company), natural philosophers could hardly ignore the new technology. While expressing some reservations, Britain's Royal Society emphasized the technology's utility for exploration and other purposes (Joseph Banks suggesting that hot air balloons might reduce the burden on heavy coaches, for instance). Members also noted and explored their utility in meteorological science. John Jeffries pioneered balloon-based observations and experiments of atmospheric phenomena in the mid-1780s and the connection between balloons and meteorology has been tight ever since (Gillespie 1984).

The potential for balloon-based climatology and meteorology isn't limited to observing the atmosphere. They are also a potential delivery system for interventions. Human intervention into the weather isn't new (it was used in a military capacity during the Vietnam War, for instance), but the threat of climate change adds an increasing impetus, a rationale, for understanding how we might control global temperatures and other climatological phenomena. Even if we manage the task of reducing carbon emissions, the time lag between reduction and climatological improvement means that the chaotic effects of climate change would be with us anyway. If global temperatures were to some extent under our control, then we could curb those costs, and much pain could be happily avoided. However, there's reason for caution, as simply developing such technologies might reduce our chances of in fact making the changes required to curb climate change, the suspicion being that there is a trade-off between carbon reduction and geoengineering. Moreover, such interventions involve new technological territory and the large-scale manipulation of complex systems; we're venturing into the unknown. Further, some geoengineering proposals require ongoing commitments from national actors, and we may not have the appropriate international governance available (let alone know how to resolve questions about responsibility). Finally, at least some worry that the whole enterprise smacks of a certain utopian pro-technological hubris. Which brings us to our second balloon.

A major aim of the SPICE project was a kind of proof-of-principle test run of a geoengineering delivery system (Macnaughten \& Owen 2011). Specifically, a tethered balloon with an attached 1-km high hose was to be released into the atmosphere and spray a small amount of water. Perhaps a scaled-up apparatus could be used to inject aerosols into the atmosphere, thus increasing the Earth's albedo by blocking sunlight. In a sense, the study would have been innocuous: a waterspraying balloon hardly seems like a threat. However, in September 2011, EPSRC postponed the release on the grounds that there had been insufficient communication with the public and discussion of impacts. This was carried out on the basis of 'stage-gate' governance, whereby researchers enter into various stakeholder dialogues at various stages of research (Stilgoe et al 2013, Macnaughten \& Owen 2011, Cooper 1990). Simultaneously, a public furore culminated in an open letter signed by more than 50 NGOs demanding the project be curtailed (the 'HOME' letter). The experiment was targeted for symbolizing a shift in emphasis from reducing carbon emissions to technological solutions which mitigate the symptoms without hitting the cause. By May 2012, the launch was cancelled by SPICE themselves, citing both a lack of governance-there are insufficient 'rules' for geoengineering research-and a potential clash of interest due to one of the project investigators having a patent application for the technology in question.

Regardless of the role played by conflicts of interest, the cancellation of a low-risk, apparently innocuous, testbed study due to both internally organized reflection on public impact and enormous 
public pressure has potential down-stream effects on the palatability of the research. Scientists and their funders must make decisions about what to research in a competitive, crowded environment. As such, the failure of a high-profile, well-funded and respected research program can signal the riskiness of engaging in that kind of research. As we've seen for GMOs in Europe, stem-cells in the US, and so forth, negative public perception and political hostility can greatly influence what science gets done.

Discussion of geoengineering has largely focused on two kinds of questions:

(1) What are the moral or legal requirements and ramifications concerning geoengineering? ${ }^{1}$

(2) How ought geoengineering research be governed? ${ }^{2}$

This already rich discussion pays little attention to the social mechanisms which underwrite and drive scientific research. On my view, such mechanisms add an important dimension to understanding geoengineering and its effective governance. Here, $I^{\prime} l l$ focus on the academic context. Industry and other research sources are likely both driven by different incentives structures and require different governance (e.g., Holman \& Bruner 2017). As such, I'll leave discussion of those contexts for later work.

In what follows, l'll first sketch a set of epistemic issues surrounding geoengineering research. With that in place, I'll turn to the two tensions which I think the SPICE case highlights. I'll then reflect on these tensions and argue that some approaches to governing geoengineering research are less attractive than they may initially appear and further suggest that the governance of geoengineering ought to be sensitive to the kinds of incentives which govern scientific research. It's worth noting that one of the tensions - those relating to 'moral hazards' and international governance-should be old news: it is the focus on insights from the philosophy of science, and the interaction between the two tensions, which underwrites what is original in what follows. In the conclusion, l'll briefly consider to what extent my discussion bears on the governance of emerging technology more generally. Although there are particular features which sets geoengineering apart from other new, powerful technologies, I'll suggest that the general lesson that the effects of governance measures need to be understood in the context of science's incentive structures is a general one. I'll also highlight the challenge this places to our traditional conception of scientists and their roles in society.

\section{Epistemic challenges to geoengineering}

Developing geoengineering technologies is not a simple prospect.

Geoengineering proposals are diverse, but typically involve one of two strategies. One set increases the Earth's albedo without intervening on global carbon, such as the SPICE project's interest in aerosol spraying. Another set reduces atmospheric carbon without intervening on emissions themselves, such as afforestation or enhanced weathering. By and large these techniques are epistemically similar due to being (1) theoretically well-understood, but (2) practically very tricky because of targeting large scale and complex systems. Let's take these in turn.

Scientific knowledge often consists in relatively simple theoretical understanding of complex systems. For instance, part of the Earth's climate absorption is determined by the amount of silicate minerals exposed to weathering. Atmospheric $\mathrm{CO}_{2}$ is dissolved into rainwater to form acids which in turn slowly dissolve ('weather') silicate rock, which is eventually carried by rivers into the oceans

\footnotetext{
${ }^{1}$ See, for instance, Mclaren 2016 for moral issues, Markusson 2013 for a legal discussion.

2 E.g., Bellamy 2016
} 
where the carbon is used by various biological organisms to form shells and the like. Thus carbon is transferred from the atmosphere to the geological carbon bank. Enhanced weathering, in effect, speeds this process by increasing the amount of exposed silicate-thus upping the Earth's carbon absorption (perhaps, but not necessarily, accompanied by the stimulated growth of phytoplankton). Or to take another example, global temperature is a function of the sun's intensity, the Earth's albedo (that is, how much sunlight is reflected back into space), and the amount of energy trapped by atmospheric greenhouse gases. As such, increasing the Earth's albedo could mitigate temperature increases driven by a more concentrated atmosphere. So, ways of increasing albedo (aerosol injection, etc...) could stabilize the Earth's temperature. Geoengineering strategies, then, piggy-back on well-understood, well-supported scientific theories.

This theoretical simplicity, however, belies geoengineering's epistemic and practical difficulty. Despite our basic theoretical understanding of the factors which contribute to the Earth's carbon budget, actually intervening on these is a vastly different proposal (Hulme 2017, Svoboda \& Irvine 2014). This is because global systems are large scale and complex. The latter feature undermines our capacity to infer from theoretical understanding to actual results. There is no guarantee, for instance, that increased exposed silicate rock (and thus increased oceanic carbon) is all that is required for those carbonates to be stored. The interdependencies of the Earth's systems are tricky customers for predictable intervention. The former feature-scale-undermines our capacity to experimentally or indirectly probe what the results of such interventions might be. The very features that make experiments scientifically desirable, the isolated, repeated manipulation of causal factors, undermines their capacity to be particularly informative of how those features play out in the bustling world beyond the experimental setup ${ }^{3}$. Further, there is no real reason to think that the effects of geoengineering will be uniform across contexts: the world is not only complex, but heterogeneous 4 .

The complexity and scale of the systems geoengineering targets, then, limits our capacity to probe and understand the risks and byproducts of actual interventions. There are, of course, various strategies scientists adopt to reduce uncertainty in these circumstances. These largely involve navigating between various surrogates, using small-scale experimentation, computational simulations, and so forth ${ }^{5}$. Further, nature sometimes provides 'natural experiments', most relevantly the 1991 Pinatubo eruption (Newhall et al 2005), which increased global atmospheric sulphuric acid, lowering average temperature by roughly half a degree for a few years. But for understanding the possibility and likely effects of actual geoengineering, field experiments are crucial. Geoengineers frequently draw allusions to the practices of medical science. In that context, extensive research on various experimental systems, such as animal trials, are carried out before human populations are put at risk. However, random controlled trials -the gold standard of evidence-based medicine (EBM) - are a crucial lynchpin, and indeed, there is at least some reason to think that the EBM folk are right to grant low credence to evidence from laboratory work (Solomon 2015, Lemoine 2017). To ascertain the effectiveness of some medical treatment we ultimately have to test it on its intended subjects. A similar lesson, I suspect, holds for geoengineering: ascertaining geoengineering's effects (intended or otherwise), effectiveness, and necessary engineering features, requires field experiments (Keith et al 2014, Dykema et al 2014). On the extreme, Robock et al claim

\footnotetext{
${ }^{3}$ Nancy Cartwright captures the problems with external validity in experiments particularly vividly (1999), see also Currie \& Levy (under review).

${ }^{4}$ I'm taking my queue for this discussion from work in the philosophy of ecology, particularly Matthewson 2011, Elliott-Graves 2017, and also Currie \& Walsh (2018).

${ }^{5}$ Philosophers have had much to say about such surrogate research recently, see, for instance, Weisberg 2012.
} 
that full deployment is required to test geoengineering technology (2010) (although see MacMynowski et al (2011)).

That geoengineering requires applied research into the effectiveness of such measures, and that such measures must be employable at large scales, necessitates a multi-disciplinary effort such as that of SPICE. Climate and atmospheric scientists, chemists, engineers, modellers, and so forth, are all required. As I'll discuss further below, although multi-disciplinarity has a positive spin in public and funding contexts, in many scientific contexts it can be unattractive. In addition to navigating the varying standards, practices and languages across disciplines, multi-disciplinary publications are often not valued in the same way that publications in the central journals of 'home' disciplines are. This is particularly true in hiring contexts, making such projects unattractive to early career researchers; and further in funding contexts, where both peer review and centralized decisions about dividing resources make a research area's reputation critical.

We can, then, identify several features of geoengineering relevant going forwards. First, research into geoengineering is necessarily speculative: that is, much of the territory is uncharted, making false starts and dead ends likely ${ }^{6}$. Second, much of the research requires explicit field-testing of both deployment technologies and climatological agents: often expensive, 'splashy' (likely to draw public attention), and, given the first point, epistemically risky. Third, the research is necessarily multidisciplinary. As we'll see, the second tension I'll discuss makes these features problematic, and undermines some of the measures intended to navigate the first tension. Let's move to those now.

\section{The first tension}

There are moral and prudential arguments pulling us both towards, and away from, further geoengineering research (Lawford-Smith \& Currie 2017). On the one hand, the availability of geoengineering technologies might undermine carbon reduction efforts. That is, the more we are able to mitigate the effects of climate change, the less urgent it will become to meet the likely radical economic, demographic and political changes that dramatic carbon reduction requires. Moreover, getting geoengineering right likely requires international agreement and governance that simply is not in place. This suggests that developing geoengineering technologies is in itself dangerous. But on the other hand, such technologies have enormous potential to hold back the worst of the damages of climate change, providing necessary breathing space while emission reduction slowly takes effect. On one side, 'arming the future' with geoengineering might in itself guarantee its need by reducing pressure on carbon reduction ${ }^{7}$. But on the other side, surely disarming the future is unconscionable ${ }^{8}$.

I'm going to assume that the potential benefits of geoengineering research are well-known and more-or-less obvious ${ }^{9}$. To quote the Oxford Geoengineering Program,

\footnotetext{
${ }^{6}$ For general discussion of the nature of speculative research, see Currie (2018)

7 This wording is from Gardiner's (2010) response to Crutzen (2006).

${ }^{8}$ In some places it is worried that methods of making geoengineering responsible could add to the apparent inevitability of the research and deployment of those technologies. As Jack Stilgoe puts it, such methods "... risk closing down decision making rather than opening it up to new possibilities" $(855,2016)$. This is a legitimate worry, but it's worth pointing out that surely not doing the research also closes down decision making.

${ }^{9}$ Indeed, geoengineering in some forms has become increasingly built into planet management. For instance, they play a role in scenarios involving planetary temperature increases remaining below 2 degrees (Tollefson 2015).
} 
Failure to conduct research may leave us in a situation where some parties might be tempted to view geoengineering as a cheap or fast-acting means to counter climate change and seek to implement an inadequately researched technique. Conversely we may decide not to implement a technique which would have been able to counteract climate change safely, but not do so as we had not conducted adequate research. Either way ignorance could pose an existential threat to our society. (OGP 2011, italics added)

Not researching geoengineering could either lead to action being taken with inadequately understood technology, or not deploying potentially life-saving technology due to a lack of knowledge.

I'll focus on the prudential arguments against geoengineering research.

Consider what Ricardo Navarro, engineer and environmental activist, has to say on the webpage of HOME, the organization behind the anti-SPICE letter.

The same countries and companies that have neglected climate change for decades, are now proposing very risky geoengineering technologies that could further disrupt the weather, peoples and ecosystems. For them geoengineering is a "perfect" excuse to claim they can keep on heating the planet because later they will cool it off with dangerous experiments. As global environmental movements, we cannot allow the geoengineers to experiment with the planet and its peoples. (from http://www.etcgroup.org/content/hands-mother-earth, accessed 23/3/2017)

Navarro believes the development of geoengineering technologies will have extremely bad consequences. First, undermining pressure for lowering carbon emissions; second, the technology is itself risky. That is, geoengineering interventions are 'dangerous experiments'. But further, the development of the technology required for geoengineering interventions carries indirect risks due to providing 'excuses' for not lowering carbon emissions. Ironically, the first claim would in fact be somewhat mitigated if only the kinds of research the second claim disallows went forward. Thus, the tension I'm interested in is actually embedded in HOME's arguments themselves.

The kind of objection Navarro voices is often discussed as a 'moral hazard', and the objection is nothing new vis-à-vis geoengineering. Another objection which I'll discuss below concerns the capacities of international communities to maintain geoengineering measures once they are implemented, and to govern the financial and environmental cost which could result. Without a good answer to those concerns, we might think that the technology's use would increase rather than alleviate harm. Worries regarding the moral hazard of geoengineering should be taken seriously, especially in light of our collective slow pace at turning off climate change's anthropogenic tap. As Mclaren puts it,

While there are many other reasons for slow progress on mitigation-from vested interests to collective action problems - we cannot definitively rule out a contribution from moral hazard around climate engineering. Moreover, given the glacial rate of progress hitherto on mitigation the simple risk of mitigation deterrence might motivate us to find ways to counteract it. (Mclaren 2016, 599).

There is also, of course, a set of more normative concerns both in Navarro's statement and others like it. These include worries about hypocrisy, justice, and hubris. Such issues are complex, and I'll leave them to one side (although see Lawford-Smith \& Currie 2017, Preston 2013, Corner \& Pidgeon 2010, Hale 2012). What interests me here is the relationship between the kinds of measures taken 
by both scientists and those interested in positively governing geoengineering in light of both this worry, and the next tension.

\section{The second tension}

The first tension-between arguments in favour of developing geoengineering technologies, and the dangers their development might bring-is fairly well understood. The second tension has received less attention. It focuses on the urgency and epistemic difficulty of geoengineering research on the one hand, and the potential conservatism of scientific research on the other. I'll focus on how science's conservatism is driven by the dynamics of career paths and the requirements of funding (see Avin forthcoming, Currie under review).

Although science's organization makes it very productive insofar as lots of research gets done, it also makes it conservative, in that research tends to 'pool' into a few-ideally promising-research programs (Weisberg 2013, Strevens 2013). The productivity of scientific research is driven by incentives towards scientific credit (awards, publications, promotions, etc...) which lead scientists to publish often, and attempt to provide output which will maximize research impact. Although intuitively we might think that 'impactful' research will be somehow radical or revolutionary, this is typically not the case. Work which is too outside the mainstream will be blocked by referees both in publication and funding, and regardless will likely not garner much attention due to being out-ofstep with thriving research programs (Stanford 2015). Although new programs certainly emerge, and sometimes achieve band-wagon status, there is a sense in which these production-boosting features of science are not diversity-boosting ${ }^{10}$. Moreover, scientists, as well as funding bodies, must make bets about which research directions will be fruitful (Turner 2016). This aspect partly explains the potential impact of the cancellation of SPICE's balloon-launch: it signals that the venture was simply too hard; a bad bet.

Geoengineering is precisely the kind of research which science's conservatism makes it tricky to actually do. As we saw in section 2, research on surrogates and proxies provides crucial but inadequate ways of filling out our theoretical knowledge, but actually figuring out how to deliver the technologies, and the results of such interventions, requires expensive field-tests. Further, due to the research's speculative nature, failures should be expected, risky 'bold' hypotheses are necessary, and thus the direction of research is difficult to predict, making the kind of specific, likely epistemic dividends which funders prefer unavailable (Currie 2018 chapter 11).

In the face of perceived risk, an additional stressor comes from the requirement for careful, fairly extensive consultation throughout research. This further gums up already slowly-moving gears (see for instance, Parson \& Keith 2013). Further, the requirement for transparency potentially puts at risk some of the incentives which makes science productive (i.e., partial ownership of the goods reaped by new discoveries). Moreover, such research is necessarily multi-disciplinary, drawing on climate modelling and material engineering, among other fields. As mentioned above, different disciplines have different expectations about evidence, publishing, and so forth. Differences in the treatment and purposes of patents between engineers and scientists is one reason why SPICE's balloon-launch was cancelled (Stilgoe et al 2013). Further, career-wise, scientists' home disciplines are often much more interested in 'core' research and publishing: too much integrated, multi-disciplinary work can actually hurt career prospects, especially for early-career researchers.

\footnotetext{
${ }^{10}$ Philosophers of science have turned their attention to how scientific incentives effect the diversity and productivity of scientific communities, and my discussion in this paragraph draws from those discussions. See, for instance, Kitcher 1995, Strevens 2003.
} 
This all makes geoengineering look like a bad bet for practicing scientists. Indeed, the attempts by scientist themselves to provide guidelines for geoengineering is testament to how important they think it is despite its unattractiveness from a career and funding perspective. Even if this doesn't stop research in geoengineering wholesale, it at least changes the kinds of people who get involved. On the plausible assumption that a diversity of personalities, research-styles, and so forth, are important for a thriving research program (O'Connor \& Bruner 2017), such decreases in diversity are problematic even beyond concerns for the justness of such programs.

\section{Navigating the tensions?}

So, we have a tension between the epistemic and social context of geoengineering and the dynamics which promote scientific success; and a tension between arguments in favour of the urgency of geoengineering research, and those emphasizing the risks of engaging in research in the first place. Although it is helpful to analyse these separately, in practice both must be navigated together, and this, as I'll show, changes how we should think about strategies the geoengineering community has adopted (purposefully or otherwise), partly in light of SPICE. The two moves I want to highlight are first, a tendency towards rebranding; second, an attempt to split the availability of geoengineering mitigation from carbon reduction strategies, and to split geoengineering research from geoengineering deployment.

Before getting to that, it will be helpful to outline the aspect of Navarro's argument which I'll focus on.

(1) Geoengineering research would enable the deployment of geoengineering technology;

(2) The capacity to deploy geoengineering technology would decrease carbon reduction;

(3) Therefore, geoengineering research would decrease carbon reduction.

By this argument, there is a coupling between geoengineering research and the capacity to deploy such technology, and a coupling between our capacity to deploy such technology and a decrease in carbon reduction ${ }^{11}$. These two dependencies capture Navarro's worry about 'excuses': if premise 2 is true, the availability (or perceived availability) of geoengineering technologies would lead at least some players (governments, businesses, etc...) to be less worried about their carbon output. As Albert Lin has put the worry:

... geoengineering could be inaccurately perceived as a comprehensive insurance policy against climate change. This misperception could create various incentives that would exacerbate the problems that geoengineering is intended to ameliorate (678).

Or, from Duncan Mclaren:

... decision makers may reduce mitigation effort, believing climate engineering to represent adequate insurance against climate risk $(2016,596)$.

Note that this 'excuse' version of 'moral hazard' comes in an explicit and implicit form. Explicitly, agents might recognise the benefits (for them) of using geoengineering as a reason to not reduce emissions; implicitly, incentives to avoid potentially costly reduction measures could have the same effect without explicitly self-interested action.

Naturally, another premise is required to get Navarro's desired conclusion: that reductions in carbon emission decreases would be negative; disastrous. I don't think that premise comes for free: the

\footnotetext{
${ }^{11}$ This argument could also be considered in terms of the perception of deployment, although it is possible that geoengineering research could actually demonstrate the practical infeasibility of some measures.
} 
kinds of social changes required for dramatic emission reduction could quite easily have negative consequences. Indeed, trying to understand what social, political and economic interventions are required-not mentioning the actual costs or benefits of such changes-is extraordinarily tricky. Under some circumstances we might choose-and choose rightly - to research, develop, and perhaps implement geoengineering measures even if we have good reason to believe they will lead to less emphasis on carbon reduction.

Ben Hale (2012) has rightly complained that the 'moral hazard' argument against geoengineering is in fact a set of quite different arguments, which often require different support and policy responses. Just as, as I'll suggest below, the term 'geoengineering' hides a large number of quite disparate practices, 'moral hazard' arguments come in various quite different forms (although see Mclaren 2016 for discussion of a broad, inclusive definition of moral hazard, which I follow here). Having said this, for my purposes, the coarse-grained argument above is suitable as it allows us to get a grip on the relationship between rebranding and decoupling - the two strategies we'll consider-and the two tensions I've just outlined.

Let's consider another, analogous argument which recognises how geoengineering measures would challenge international governance. After all, geoengineering requires ongoing maintenance (Wong 2017), and there is at least potential for a failure of that maintenance to lead to 'exit shock'; a much faster (and thus more damaging) warming than otherwise (Irvine 2015). Moreover, the winners and losers of various geoengineering measures are likely to be varied, and ensuring that just process and responsibility (whatever that should look like) is achieved is not only difficult, but potentially involves new international agreements and discussions. The analogous argument could go as follows:

(1) Geoengineering research would enable the deployment of geoengineering technologies;

(2) Having the capacity to deploy geoengineering technology without proper global governance in place would be disastrous;

(3) Proper global governance is not in place;

(4) Therefore, geoengineering research would be disastrous.

As with the previous argument, this relies on the coupling of research with the capacity to deploy, and a coupling of those capacities with bad outcomes ${ }^{12}$. Szerszynksi et al (2013) argue that solar radiation management is "... a form of technology which is 'inherently political' in the sense of being unfavourable to certain patterns of social relations and favourable to others" (2811). Specifically, they claim that such technology is unfavourable to democratic governance. If such arguments hold water, and research and deployment are coupled, then insofar as democratic governance matters, the consequences of geoengineering research could be dire. In addition to this structural feature, both arguments share the properties of, first, turning on empirical and governance issues which are outside of what we take the usual sphere of scientific research to include, and second, involving the behaviour of actors (the public, governments, etc...) which scientists have limited control over. These two features will be crucial for my arguments. Again, even if these arguments cannot be mitigated, the urgency of geoengineering measures might ultimately be judged to trump such outcomes: perhaps one disaster is preferable over another.

\section{1 "Rebranding"}

Since SPICE cancelled its launch, there has been a tendency for scientists interested in geoengineering to adopt a kind of 'divide and conquer' strategy: not all geoengineering measures

\footnotetext{
${ }^{12}$ See Svoboda \& Irvine (2014) for a pessimistic discussion of the ins and outs of developing a compensation scheme for those harmed by geoengineering efforts, and Wong et al (2014) for a response.
} 
are equal, and indeed shouldn't be unified under one banner ${ }^{13}$. Even before 2012, the so-called 'Asilomar 2' meeting in late March 2010 split 'geoengineering' into Climate Intervention (increasing the Earth's albedo) and Carbon Remediation (post-emission carbon reduction) (see Kintisch 2010). The 2015 National Academies' National Research Council report also recommended rebranding:

... the committee believes that these approaches are more accurately described as "climate intervention" strategies-purposeful actions intended to curb the negative impact of climate change-rather than engineering strategies that imply precise control over the climate (2015)

Another example is the Leverhulme Centre for Climate Change Mitigation, a $f 10$ million project funded in late 2015 focusing on enhanced weathering, which notably avoids the term 'geoengineering' ${ }^{14}$. It's worth reiterating that 'strategy' needn't imply explicit agency. Given the dark cloud hanging over geoengineering, there are incentives rewarding rebranding, so we needn't postulate specific strategies on scientists' part (although I'm sure there is some of that).

The line between epistemically valid distinctions and mere strategic rebranding is vague. Undoubtedly, intervention and remediation are epistemically very different (indeed, I divided geoengineering along just the same lines in my own treatment above), and of course the control implied by 'engineering' is a far cry from what actual geoengineering measures would look like in practice. 'Rebranding', then, is not without theoretical and empirical grounds. Further, the term 'geoengineering' in many ways plays into attempts to stop it. Employing a coarse umbrella-term in referring to a wide range of different activities allows diverse scientific projects to be tarnished with the same brush. Consider the following from Lin:

Geoengineering, a third category of climate policy options, is a catchall term for an array of unconventional, untested and frequently risky proposals (674).

How unconventional, untested, and risky geoengineering proposals are varies (as does their potential effectiveness): even if some geoengineering prospects have potentially disastrous effects, others might be more-or-less benign. Further, as Reynolds (2011) has argued, some forms of geoengineering (such as iron fertilization) already fall within existing regulatory structures, while others do not. Putting mirrors in space, shooting aerosol into the atmosphere, and adding silicates to agricultural dusting are very different ideas, and surely lumping them together is problematic. As Clare Heyward has put it ${ }^{15}$,

Technically, CDR and SRM are quite different and discussing them together under the rubric of geoengineering can give the impression that all the technologies in the two categories of response always raise similar challenges and political issues when this is not necessarily the case. (Heyward 2013, 21)

\footnotetext{
13 'Rebranding' is just one aspect of a broader discussion concerning the framing of geoengineering. For instance, should it be framed as a last-ditch response to climate emergency, or an aspect of ongoing sustainable climate management? Although I leave these broader questions here, see Makusson et al 2013 and Huttunen \& Hilden 2013 for discussion.

${ }^{14}$ See: https://www.sheffield.ac.uk/news/nr/climate-change-mitigation-leverhulme1.531199?utm content=buffer3a78a\&utm medium=social\&utm source=twitter.com\&utm campaign=buffer thanks to Holly Lawford-Smith for the example.

${ }^{15}$ Heyward, rather than subsuming geoengineering efforts into mitigation or adaptation, recommends a more sophisticated framework involving 5 levels of response to climate change, in part differentiated on the basis of the aims underlying countering climate change. On my view, this kind of approach is a significant improvement over typical framing.
} 
Having said this, we shouldn't be so naïve as to think that trying to avoid the dirt which has attached to geoengineering is not playing a role in rebranding recommendations.

Regarding the second tension, rebranding appears a sensible move: earlier I argued that one reason that SPICE's cancellation could be problematic is it making geoengineering a bad bet for scientists and their funders: it lands in the 'too hard' basket. A successful rebranding could duck these perceptions and make research into (let's call it) 'schmeogeneering' a more attractive prospect. Especially given the more outlandish claims about geoengineering's dangers, decoupling proposals from the term is often well-motivated and, perhaps, necessary. However, I think rebranding becomes problematic when we consider the first tension, and in particular the second premise of the arguments I discussed in the last section.

Distinguish between perceived and actual risk. Navarro and others have a clear perception that geoengineering being (or being perceived as) a live option will undermine carbon reductionperhaps due to an intentional strategy on the part of the 'geoengineers' (highly unlikely, to my mind), or simply due to the political and economic pressures on governments and other actors to not implement carbon reduction (more likely, to my mind). This involves a set of empirical claims which are extremely tricky to get traction on (although see Moreno-Cruz 2015, Rostle 2016) - so the actual threat is hard to determine. But the perceived threat is high, and it is this perception which mattered for the public pressure put on SPICE.

In the good case, our perception of risk aligns with actual risk ${ }^{16}$. However, often these misalign: our perception of risk might outrun, or underrun, the actual risk. Consider the following circumstances. $A$ : our perception of the risks of geoengineering are highly inflated given the actual risk; $B$ : our perception of the risks of geoengineering are either equal to, or underestimate, actual risk. In circumstance $A$, rebranding is (if perhaps somewhat underhanded) less problematic: given a (mistaken) belief among the public, policy makers, or within scientific communities, rebranding can give the technology a new lease on life. However, in circumstance $B$ rebranding is extremely problematic: here, an underhanded strategy is used to enable dangerous research.

Are scientists involved in geoengineering in a good position to decide whether we are in circumstances $A$ or $B$ ? In my view, this turns on which dangers we focus on. Regarding some of the unintended consequences of climate interventions scientific understanding is, perhaps, just the thing. Navarro's worry about 'dangerous experiments' springs to mind. For instance, what might count as a 'safe threshold' for geoengineering field trials is a question which scientists are likely wellpositioned to answer (or at least best-positioned to answer). However, see Stilgoe (2016 p860), and below, for challenges to the thought that thresholds are a sufficient governance measure. However, regarding other risks, specifically the opportunity geoengineering could provide to those who wish to avoid the cost and drastic changes of carbon reduction, or whether the right global governance is in place to ensure the ongoing maintenance and possible redress required for geoengineering efforts, I see no reason to think that scientists are in a good position to make judgments. Scientists are right to claim privileged epistemic access to those domains that they are trained to understand; the socio-economic and political costs of their research is not one of them. To put this another way: the arguments above rely on coupling the capacity to deploy geoengineering technologies with carbon-emission excuses or bad global governance-but scientists are not experts in moral hazards or global governance. I've suggested that for rebranding to be justified, we need good reason to think that the second premise is false. Is it? How would we tell? In particular: it is not clear to me

\footnotetext{
${ }^{16}$ This is a version of what Lewis (1980) has generally called the 'principal principle', but applied to risk in particular.
} 
that scientists themselves, or those involved in discussions with them, are in a good epistemic position to make that judgment (perhaps they ought to be, a point I'll raise below). As such, the strategy is problematic.

Focusing on moral hazard arguments, we have at least some access to what the social effects the capacity to deploy-or the perception of it-might be. Albert Lin (2013) has argued that many underestimate the moral risk pertaining to geoengineering. His argument depends, on the one hand, on an analogy between the history of climate change adaptation and geoengineering, and on the other hand, psychological research about the various biases which underwrite moral hazard. Regarding the former, he points out that where adaptation measures are potentially disruptive and were perceived as the result of a failure, "... it is more likely that geoengineering proposals will be perceived-at least by some-as a simple solution to climate change" (684), making geoengineering attractive in ways likely to lead to moral hazards. Regarding the latter, Lin summarizes the diverse evidence in favour of risk compensating behaviours, concluding "...The increasingly dismissive views regarding the possibility of a geoengineering moral hazard are surprising because the phenomena of moral hazard and risk compensation are undisputed in a variety of other contexts" (692). It's also worth adding (as Lin does) the role of economic and social incentive structures which make it in the interests of some groups to actively encourage geoengineering as a means of undermining pressure for carbon emission reduction (that is, the explicit reading of 'excuse').

This discussion has assumed that the epistemic specialities of scientists are stable-and this is far from necessary. One response to the argument of this section (helpfully urged by a referee for this journal) is to retrain scientists - change their role and expected skill sets. That is, demand that scientific training in values goes beyond research ethics, to include considerations of the sociopolitical ramifications of their work. In principle, I could not agree more. In practice I have a few reservations. First, if only a small fraction of scientific research has the potential impact that demands such considerations, it seems overkill to revamp both scientific pedagogy and what we expect of scientists in light of it. Second, if the recommendations were to be more restricted to those researching technologies with such impacts, such actions will likely exacerbate the second tension. Third, I'm inclined to see division of epistemic labour as a strength of our epistemic communities, and am loathe to demand such a broad knowledge base be required of each individual. A solution in light of this, of course, is the development of roles within scientific communities that specifically bridge the gap between traditional scientific knowledge and sociopolitical aspects. Regardless of climate change and geoengineering the project of re-imagining the relationship between science and society is unquestionably important (Douglas 2009, Kitcher 2003). In the meantime, however, the Earth's climate clock is ticking.

\subsection{Decoupling}

There is a common theme among groups seeking to develop responsible frameworks for geoengineering. They insist-loudly, and repeatedly-that the development of such technology cannot replace carbon reduction efforts. These, in a sense, are attempts to decouple the development of geoengineering technology from efforts to reduce carbon footprints; or an alternative strategy: decouple the development of geoengineering knowledge from geoengineering application.

Consider this from the National Research Council:

There is no substitute for dramatic reductions in greenhouse gas emissions to mitigate the negative consequences of climate change. (NRC 2015) 
Or this from the Oxford Geoengineering Programme's summary of the risks motivating the 2011 'Oxford principles':

It is important that those working in the field of geoengineering are clear that it is no panacea for climate change and express that clearly in their interactions with the media and society. Emission reductions are essential - geoengineering research is required because, while essential, reductions alone may not be sufficient to avoid dangerous climate change. (OGP 2011)

Here, we attempt to overcome the source of the first tension: the coupling of knowledge of climate change and action to reduce climate emissions. There is another, less overt, strategy which is similar, again from the NRC:

... any future decisions about albedo modification will be judged primarily on questions of risk, and there are many opportunities to conduct research that furthers basic understanding of the climate system and its human dimensions-without imposing the risks of large-scale deployment-that would better inform societal considerations. (NRC 2015)

Here the strategy is to decouple geoengineering knowledge from geoengineering deployment. If it were possible to have a good understanding of geoengineering principles, without enabling the indirect risks of deployment, the first tension's teeth would be surgically removed.

Moreover, decoupling research from deployment could make other aspects of geoengineering governance more straightforward. One suggestion for the governance of field experiments, for example, is to suggest safety limits for test interventions (e.g., Parson \& Keith 2013). However, for this to be an effective solution, decoupling is required: "... appeals to safety are to miss the point that it is broader political, social, and ethical concerns that make the proposals so contentious" (Bellamy 2015, 154). Stilgoe $(2015,2016)$ makes this argument forcefully. By conceiving of geoengineering technology as itself an experiment (as opposed to the product of experiments), the concerns of research ethics-informed consent, for example-become applicable to the development of those technologies. Considering the global nature of some proposals, we all might be considered subjects of such 'experiments' (see also Szersynski et al 2013).

Additionally, decoupling strategies plausibly lessen the second tension as well. That tension turned on the nature of geoengineering research-particularly its need for field experiments as well as bountiful oversight from public and policy-makers-clashing with various aspects that make for effective science. If we could decouple scientific research from its deployment, or from political decision-making, then the need for large amounts of oversight-slowing it down, making it unattractive, or otherwise undesirable-would itself decrease. Or at least, that oversight would be much less likely to lead to SPICE-like outcomes.

However, let's consider again the second premise of the argument at hand:

The capacity to deploy geoengineering technologies would decrease carbon reduction.

I agree that geoengineering is not a replacement for carbon reduction, and I agree that the capacity to deploy geoengineering techniques should not decrease carbon reduction, as the de-coupling statements claim. However, this is not what is at issue: what matters is whether having the capacity would in fact decrease carbon emissions. Analogous claims could be made about global governance.

Scientists simply claiming or demanding that such decoupling occurs is not sufficient. Scientists, and the bodies which regulate scientific research, have insufficient say over how various technologies are 
deployed for their demands to have much relevance. To the first tension, the concerns driving the indirect risk are not primarily about what scientists will do, but about what governments and other agents will do vis-à-vis their carbon reduction strategies in light of the availability of geoengineering technology. Further, the second tension arises in part from the need to monitor and control geoengineering from (as it were) the outside: this suggests that scientists themselves are just the wrong folk to be driving such decoupling.

Here is a good place to discuss an ambiguity in the notion of decoupling research from deployment. On one understanding, carrying out geoengineering's required research requires provisioning the capacity for deployment. On another-more challenging-understanding, research requires deployment. Regarding this latter version, Stilgoe says, "... the absence of either a hermiticallysealed scalable laboratory or a control run world blur any line between research and deployment" $(2016,859)$. I suspect the more extreme view is overstated. Any technology, particularly those as powerful as some geoengineering technologies could be, involve uncertainty prior to deployment (this was certainly true of nuclear weaponry). Such uncertainty can be mitigated via limited field trials combined with modelling and so on. There is nothing particular that I can see that sets geoengineering apart from any other powerful, potentially global technology. Having said this, Stilgoe is surely correct that the requirement of field trials is a requirement that geoengineering be deployed on a restricted scale for research purposes. Regardless, the weaker sense of coupling is sufficient to drive my discussion here.

Where in my discussion of rebranding I questioned whether scientists are in a good epistemic position to judge the truth or otherwise of claims like premise 2 , here I question whether governance measures targeted at scientific research could be effective in allaying these tensions. The locus of the risk is the perception of research, not the research itself (that is, unless full deployment is required for research purposes). And it is unlikely that stage-gating and other processes involving intervening on the path of research will effect that locus. This is not to say that such governance procedures are not important, useful or necessary for a just science. Rather, they are not solutions to the factors underwriting the first tension. And worse, they likely exacerbate the second tension. Ongoing dialogue with stakeholders likely promotes the various features which already make geoengineering research a daunting prospect for scientists trying to make careermaking or breaking bets about the success of research directions, and those trying to decide where to best place science funding.

If it is right that most of the concerns about the development of geoengineering technologies is not about the technology per se, but rather how the availability of that technology plays out in public, political and global spheres, then it is unclear why governance structures suggested for geoengineering research which include various forms of stakeholder involvement are of help. Stakeholder involvement in ongoing research, it strikes me, matters crucially when the social outcome of a technology's trajectory depends on how that research actually plays out. Ensuring that a diversity of voices are heard during that process, and in part making the research's continuation dependant on those voices as stage-gating does, are then ways of ensuring that research trajectory tends towards the less harmful, and most beneficial. And surely some of these matters make a difference in the geoengineering case. However, at least given arguments from moral hazard and global cooperation, governing the scientists is besides the point. What we need instead are mechanisms which tie ongoing research to funding of mitigation efforts, on the one hand, and the development of international agreements on the other. In a sense, this suggests less that stakeholder voices be heard in the context of scientific research, and more that scientific voices be heard in national and international governance. It's not my job here to provide suggestions for what 
such mechanisms should be but these considerations do suggest that pressure should be put on governments and other more powerful bodies, rather than scientific researchers themselves, if we want to achieve such decoupling (Lin 2015).

Scientific research does not operate in a vacuum from the rest of science; and neither then do attempts to govern it. Interventions on geoengineering have been discussed both at a global level (e.g., Virgoe 2009) and concerning local research (e.g., Stilgoe et al 2013); as well as at the level of deployment and the level of research (assuming such things can be decoupled). In their call for a geoengineering code of conduct, Hubert et al envision a code providing "flexible governance [which] encourages early co-operation and co-ordination of research, equity and sustainable development [as well as] promote precaution, risk assessment, public participations, and transparency" (537). Macnaughten and Owen claim "For geoengineering to progress, its developers must be mindful of wider impacts from the outset, and it must proceed under robust governance mechanisms" (293). The emphasis is on science proceeding justly and safely. I am all for this. But given the high-risk game scientific careers and funding are, the consequences of project failure-and even of making an area of research more difficult than another-can confound research much more than is typically realized. And the arguments for geoengineering are strong enough for this to be a real concern.

The upshot of this is not a demand that we stop or reduce 'red tape' being added to geoengineering. Rather, if such measures are to be put in place, other policies which mitigate the resultant unattractiveness of the science ought to be put in place too. Concrete suggestions are above my paygrade in this paper but insofar as scientists are credit-driven agents, then the addition of new credit could off-set the drag which important governance may add.

\section{Conclusion}

On the $24^{\text {th }}$ of March 2017 group of scientists from Harvard announced a multi-year project investigating the feasibility of very similar geoengineering technologies as SPICE. Indeed, their plans include the launch of a water-spraying balloon in early $2018^{17}$. Like SPICE, they have also committed to continual monitoring and discussion with stake holders. It is striking, considering the apparent innocuousness of the proposed experiment, that SPICE's failure could take some of the blame for there being no field experiments in aerosol spraying for over 6 years. It will be interesting to see whether this next attempt fares better.

Given the previous discussion, if the possible benefits of geoengineering are to be realized, (1) geoengineering research should be properly incentivised (or at least not de-incentivised) and (2) research should be somehow buffered from the tricky couplings with 'excuses' and failures of international governance. However, achieving this appears to be beyond the scope of the scientists themselves: climate scientists/engineers do not have special insight into socio-politico-economic contexts and regulation of science has limited capacity to influence how that science is used, or its general effects. Measures such as stage-gating are a good way of ensuring certain kinds of dialogue occur, but there is very little in it for scientists, and has very little capacity to manage the perceptions of geoengineering, the incentive structures which underwrite moral hazards, and to ensure sufficient global governance is in place. And moreover, too much, or too heavy-handed governance, I think, has the potential to be a real disincentive for scientists to enter into an already unattractive field.

\footnotetext{
${ }^{17}$ Technically, where SPICE were focused on the engineering challenges of deployment, the Harvard group is interested in which aerosols would be effective.
} 
What lessons, if any, are there for the governance of emerging technology generally? It is important to note that the tensions between geoengineering research, deployment and safety turn in part on the specific features of the proposed technology: its reliance on international cooperation, the possibility of moral risk, and the large-scale nature of the interventions. Whichever tensions arise for other technologies are likely to be context-specific as well. Having said this, I do think there are a few points worth emphasizing generally. First, the consequences of governance measures should be considered in the context of science's 'ecosystem': the incentives and drivers which shape research. Developing technology safely is crucial, but some measures to do so likely undermine the capacity for the technology being developed at all. Assuming we do want the technology to be developed (and this is no foregone conclusion!) we should then consider how to mitigate the disincentives introduced to keep technological development safe. Second, reflecting on geoengineering makes it clear that technological research is not separate from the social, economic and ecological consequences of its use. As our tech becomes increasingly powerful, it becomes increasingly pressing to re-evaluate both how science is governed, and the role of the 'scientist' itself.

The late $18^{\text {th }}$ Century successful balloon launch wasn't only of a balloon, but of a set of fruitful research programs: by capturing the public imagination, scientific research was also pulled to the technology's possibility. The early $21^{\text {st }}$ Century failure to launch a balloon has potentially had the opposite effect: here, public imagination was turned against the idea of geoengineering, and so too was scientific research pulled away. This needn't turn out to be the end of the story, of course, but a successful defence and motivation of geoengineering must be sensitive to various tensions. Potentially, the crucial move is to find a way to enforce decoupling in the senses I've discussed, and not only within science, but beyond it as well. And I'm inclined to think that something should be worked out, because to re-iterate a quote from earlier, in the face of climate change ignorance itself poses an existential threat to our society. 


\section{Bibliography}

Avin, S. (forthcoming). Centralized Funding and Epistemic Exploration. The British Journal for the Philosophy of Science.

Bellamy, R. (2016). A sociotechnical framework for governing climate engineering. Science, Technology, \& Human Values, 41(2), 135-162.

Cartwright, N. (1999). The dappled world: A study of the boundaries of science. Cambridge University Press.

Cooper, R. G. (1990). Stage-gate systems: a new tool for managing new products. Business horizons, 33(3), 44-54.

Corner, Adam., \& Pidgeon, Nick. 'Geoengineering the Climate: The Social and Ethical Implications', Environment Magazine 52/1 (2010), pp. 24-37.

Currie, A \& Levy A (under review). Why Experiments Matter.

Currie, A., \& Walsh, K. (2018). Newton on Islandworld: Ontic-Driven Explanations of Scientific Method. Perspectives on Science, 26(1), 119-156.

Currie, A. (under review). Well-Adapted Science, Creativity \& Existential Risk.

Currie, A. (2018). Rock, Bone \& Ruin: an optimist's guide to the historical sciences. MIT Press.

Douglas, H. (2009). Science, policy, and the value-free ideal. University of Pittsburgh Press.

Crutzen, P. J. (2006). Albedo enhancement by stratospheric sulfur injections: a contribution to resolve a policy dilemma?. Climatic change, 77(3), 211-220.

Dykema, J. A., Keith, D. W., Anderson, J. G., \& Weisenstein, D. (2014). Stratospheric controlled perturbation experiment: a small-scale experiment to improve understanding of the risks of solar geoengineering. Phil. Trans. R. Soc. A, 372(2031), 20140059.

Elliott-Graves, A. (2016). The problem of prediction in invasion biology. Biology \& Philosophy, 31(3), 373-393.

Gardiner, Stephen. 'Is 'Arming the Future' with Geoengineering Really The Lesser Evil? Some Doubts About Intentionally Manipulating the Climate System', Stephen Gardiner, Dale Jamieson, Simon Caney, \& Henry Shue (Eds.) Climate Ethics: Essential Readings (Oxford: Oxford University Press, 2010).

Gillespie, R. (1984). Ballooning in France and Britain, 1783-1786: aerostation and adventurism. Isis, 75(2), 249-268.

Hale, B. (2012). The world that would have been: Moral hazard arguments against geoengineering. Engineering the climate: The ethics of solar radiation management, 113-131.

Heyward, C. (2013). Situating and abandoning geoengineering: a typology of five responses to dangerous climate change. PS: Political Science \& Politics, 46(1), 23-27.

Holman, B., \& Bruner, J. (2017). Experimentation by industrial selection. Philosophy of Science, 84(5), 1008-1019. 
Hubert, A. M., Kruger, T., \& Rayner, S. (2016). Geoengineering: Code of conduct for geoengineering. Nature, 537(7621), 488-488.

Hulme, M. (2017). Calculating the Incalculable: Is SAI the Lesser of Two Evils?. Ethics \& International Affairs, 31(4), 507-512.

Wong P-H. (2017) Maintenance required: the ethics of geoengineering and post-implementation scenarios. Ethics Policy Environ. 17/2, 186-191.

Irvine, P. J. (2015): Initial Climate Response to a Termination Shock, (Geophysical Research Abstracts, Vol. 17, EGU2015-4810, 2015), General Assembly European Geosciences Union (EGU) (Vienna, Austria 2015)

Kitcher, P. (2003). Science, truth, and democracy. Oxford University Press.

Kitcher, P. (1995). The advancement of science - Science without legend, objectivity without illusions. The Advancement of Science-Science without Legend, Objectivity without Illusions. Oxford University Press.

Kintisch, E. (2010). 'Asilomar 2'Takes Small Steps Toward Rules for Geoengineering. Science, $328(5974), 22-23$.

Lawford-Smith, H., \& Currie, A. (2017). Accelerating the carbon cycle: the ethics of enhanced weathering. Biology Letters, 13(4), 20160859.

Lewis, D. (1980). A subjectivist's guide to objective chance. In Ifs (pp. 267-297). Springer Netherlands.

Lemoine, M. (2017). Animal extrapolation in preclinical studies: An analysis of the tragic case of TGN1412. Studies in History and Philosophy of Science Part C: Studies in History and Philosophy of Biological and Biomedical Sciences, 61, 35-45.

Lin, A. C. (2015). The Missing Pieces of Geoengineering Research Governance. Minn. L. Rev., 100, 2509.

Lin, A. C. (2013). Does geoengineering present a moral hazard? Ecology LQ, 40, 673.

Luokkanen, M., Huttunen, S., \& Hildén, M. (2014). Geoengineering, news media and metaphors: Framing the controversial. Public Understanding of Science, 23(8), 966-981.

MacMynowski, D. G., Keith, D. W., Caldeira, K., \& Shin, H. J. (2011). Can we test geoengineering?. Energy \& Environmental Science, 4(12), 5044-5052.

Macnaghten, P., \& Owen, R. (2011). Environmental science: good governance for geoengineering. Nature, 479(7373), 293-293.

Matthewson, J. (2011) 'Trade-offs in model-building: A more target-oriented approach', Studies In History and Philosophy of Science Part A, 42: 324-333.

Markusson, N., Ginn, F., Singh Ghaleigh, N., \& Scott, V. (2014). 'In case of emergency press here': framing geoengineering as a response to dangerous climate change. Wiley Interdisciplinary Reviews: Climate Change, 5(2), 281-290.

McLaren, D. (2016). Mitigation deterrence and the "moral hazard" of solar radiation management. Earth's Future, 4(12), 596-602 
Moreno-Cruz, J. B. (2015). Mitigation and the geoengineering threat. Resource and Energy Economics, 41, 248-263.

National Academies. (2015). Climate Intervention Is Not a Replacement for Reducing Carbon Emissions. (http://www8.nationalacademies.org/onpinews/newsitem.aspx?RecordlD=02102015, retrieved March 23 ${ }^{\text {rd }}$, 2017)

National Research Council (2015). Climate intervention: carbon dioxide removal and reliable sequestration. National Academies Press.

Nature, 2012. A charter for geoengineering. Nature 485, 415 (editorial).

Newhall, C. Hendley, J \& Stauffer, P. (2005). The Cataclysmic 1991 Eruption of Mount Pinatubo, Philippines. U.S. Geological Survey Fact Sheet 113-97, (https://pubs.usgs.gov/fs/1997/fs113-97/)

O'Connor, C., \& Bruner, J. (2017). Dynamics and diversity in epistemic communities. Erkenntnis, 119.

Oxford Geoengineering Program. (2011). 'Oxford Principles' vital for geoengineering research.

Parson, E. A., \& Keith, D. W. (2013). End the deadlock on governance of geoengineering research. Science, 339(6125), 1278-1279.

Preston, C. J. (2013). Ethics and geoengineering: reviewing the moral issues raised by solar radiation management and carbon dioxide removal. Wiley Interdisciplinary Reviews: Climate Change, 4(1), 2337.

Preston, C. J. (2017). Carbon Emissions, Stratospheric Aerosol Injection, and Unintended Harms. Ethics \& International Affairs, 31(4), 479-493.

Reynolds, J. (2011). The regulation of climate engineering. Law, Innovation and Technology, 3(1), 113-136.

Robock, A., Bunzl, M., Kravitz, B., \& Stenchikov, G. L. (2010). A test for geoengineering?. Science, 327(5965), 530-531.

Soler, L., Trizio, E., \& Pickering, A. (Eds.). (2016). Science as It Could Have Been: Discussing the Contingency/Inevitability Problem. University of Pittsburgh Press.

Solomon, M. (2015). Making medical knowledge. Oxford University Press, USA.

Stanford, P. K. (2015). Unconceived alternatives and conservatism in science: The impact of professionalization, peer-review, and big science. Synthese, 1-18.

Stilgoe, J., Owen, R., \& Macnaghten, P. (2013). Developing a framework for responsible innovation. Research Policy, 42(9), 1568-1580.

Stilgoe, J. (2016). Geoengineering as collective experimentation. Science and engineering ethics, 22(3), 851-869.

Stilgoe, J. (2015). Experiment earth: Responsible innovation in geoengineering. Routledge.

Strevens, M. (2003). The role of the priority rule in science. The Journal of philosophy, 100(2), 55-79.

Strevens, M. (2013). Herding and the quest for credit. Journal of Economic Methodology, 20(1), 1934. 
Szerszynski, B., Kearnes, M., Macnaghten, P., Owen, R., \& Stilgoe, J. (2013). Why solar radiation management geoengineering and democracy won't mix. Environment and Planning A, 45(12), 28092816.

Svoboda, T., \& Irvine, P. (2014). Ethical and technical challenges in compensating for harm due to solar radiation management geoengineering. Ethics, Policy \& Environment, 17(2), 157-174.

Tollefson, J. (2015). The 2 C dream. Nature, 527(7579), 436.

Turner, D. D. (2016). A second look at the colors of the dinosaurs. Studies in History and Philosophy of Science Part A, 55, 60-68.

Virgoe, J. (2009). International governance of a possible geoengineering intervention to combat climate change. Climatic Change, 95(1), 103-119.

Weisberg, M. (2013). Modeling herding behavior and its risks. Journal of Economic Methodology, 20(1), 6-18.

Weisberg, M. (2012). Simulation and similarity: Using models to understand the world. Oxford University Press.

Wigley, T. M. (2006). A combined mitigation/geoengineering approach to climate stabilization. Science, 314(5798), 452-454. 